\title{
El pensamiento religioso de Vicente Rocafuerte
}

\author{
Mariano Fazio Fernández
}

Pontificia Universidad de la Santa Cruz. Roma

Vicente Rocafuerte (1783-1847), presidente del Ecuador entre 1835 y 1839, presenta un pensamiento religioso rico en matices, que se manifestará en sus acciones de gobierno y en sus escritos, configurando un ejemplo significativo de la mentalidad dominante de algunas élites intelectuales hispanoamericanas entre 1820-1845. Las circunstancias del Ecuador de ese momento obligaron a Rocafuerte a adecuar las posiciones teóricas más radicales, aunque sin desmentir completamente su visión religiosa liberal y regalista, que constituirá un precedente del enfrentamiento entre Iglesia y Estado en la segunda mitad del siglo XIX.

PALABRAS CLAVE: Rocafuerte, liberalismo, relaciones Iglesia-Estado.

This is evident in his deeds as president and also in his writings, and hence he is a significant example of the predominant mentality of some of the Latin-American intellectual circles in the years between 1820 and 1845. The prevail-ing circumstances in Ecuador at that time forced Rocafuerte to adapt his more radical theoretical positions, although without totally renouncing his liberal and imperial vision that will become the precedent to the confrontation between the Church and the State in the second half of the $19^{\text {th }}$ Century.

KEYwORDS: Rocafuerte, liberalism, Church-State relationship.

Los investigadores que intentaron bucear en la rica personalidad de Vicente Rocafuerte han llegado a conclusiones diversas al abordar su pensamiento religioso ${ }^{1}$. Buen católico para unos, semi-protestante para otros; protector o detractor de la Iglesia Católica en el Ecuador; hereje u ortodoxo, Rocafuerte se presenta en su aspecto religioso como un problema para dilucidar.

1 Véase Carbo, Pedro: Americanos ilustres. Don Vicente Rocafuerte, en $t$. I de Colección Vicente Rocafuerte (en adelante VR), Quito, 1983, I, pág. 84; Jijón y Caamaño, Jacinto: Política Conservadora, Quito, sin fecha, pág. 169; Mecum Kent.: Vicente Rocafuerte. El Prócer Andante, Guayaquil, 1983, pág. 12; Patee, Richard: Gabriel García Moreno y el Ecuador de su tiempo, México 1944, págs. 93-95; Rodríguez, Jaime: Estudios sobre Vicente Rocafuerte, Guayaquil, 1975, pág.4; Tobar Donoso, Julio: La Iglesia Ecuatoriana en el siglo XIX, de 1809 a 1845, Quito, 1934, passim; Salvador Lara, Jorge: "Vicente Rocafuerte", en $t$. XX de Gran Enciclopedia Rialp, Madrid, 1979, pág. 353; Velasco Ibarra, José María: Teorías Políticas de Rocafuerte, en tomo I de VR, págs. 59-63. 


\section{La construcción de un pensamiento religioso (1783-1833)}

Es bastante conocida la trayectoria vital de Rocafuerte, quien, antes de asumir la primera magistratura del Ecuador, desempeñó un sinnúmero de actividades en favor de la independencia de los países latinoamericanos. Nacido en el seno de una familia guayaquileña sin antecedentes anti-clericales - su padre, don Juan Antonio Rocafuerte y Antoli, fue Alguacil Mayor de la Inquisición-, transcurre su adolescencia y primera juventud en París, donde entra en contacto con el ambiente de la Ilustración. Una vez en América se moverá por la geografía continental y escribirá diversas obras en las que se vislumbran algunos elementos de su concepción religiosa. Entre 1824 y 1829 residirá en Londres, como diplomático al servicio del gobierno mexicano. En México, donde permanecerá hasta su regreso al Ecuador, publicará la obra más importante en lo que respecta a su pensamiento religioso: "Ensayo sobre la Tolerancia Religiosa".

Del estudio detallado de sus obras y de su epistolario se puede concluir que los primeros escritos, editados entre 1821 y 1824 , presentan un primer esbozo de su doctrina religiosa. Los principales puntos de esta doctrina serían los siguientes: la religión es un elemento esencial del comportamiento humano y del orden social: los hombres religiosos serán buenos ciudadanos. El cristianismo evangélico o primitivo contiene los elementos fundamentales de la religión favorable a la armonía social. Por otra parte, la participación en política de los eclesiásticos nada tiene que ver con el espíritu evangélico. En este sentido político ha de interpretarse la posición anticlerical de Rocafuerte; anticlericalismo que le lleva a decir que escribió el "Ensayo Político" "contra los Borbones, contra el Papa y el Federalismo"2.

Paralelamente, crece en este primer período en Rocafuerte la influencia protestante. Uno de los grupos que más honda huella dejará en el alma de don Vicente es el de los cuáqueros. También se relaciona con la Iglesia Unitaria, manifestación del protestantismo racionalista. Dice Mecum que "con miembros de estos grupos, conocidos por sus opiniones humanitarias y actividades reformistas, (Rocafuerte) visitó bancos de ahorro, escuelas lancasterianas, escuelas dominicales, sociedades bíblicas y prisiones

2 Rocafuerte a don Pedro Gual, Maracaibo, 27 de noviembre de 1823, en Rodríguez, Jaime, Estudios ..., n. ${ }^{\circ} .11$, pág. 55. 
modernas, cada una de las cuales representaba para él un posible medio para educar a las masas hispanoamericanas e instruirlas en las virtudes morales de honestidad, ahorro, aseo, e industria"3.

El lapso de tiempo comprendido entre 1824-1829 —el período londinense-constituye los años importantes en el desarrollo del sistema religioso de Rocafuerte. Los núcleos conceptuales de su pensamiento serían los siguientes: en primer lugar, ha forjado un concepto de religión similar al del cuaquerismo, identificado con un sentimiento interior, con prescindencia del dogma. Su doctrina de la tolerancia se deduce de esta misma concepción religiosa: cada hombre tiene derecho a dirigirse a Dios según le dicte su propia conciencia $-\mathrm{y}$ en esto coincide con la doctrina católica de la libertad religiosa—, pero soslaya el deber de la conciencia de buscar la verdadera religión. Este "sentimiento" pertenece a la esfera individual, coto cerrado para la intervención del Estado, que ha de mantenerse neutral. En segundo lugar, observamos un marcado galicanismo en su concepción de la independencia de las iglesias nacionales. La curia romana debe permanecer lo más ajena posible al gobierno de las iglesias locales, las cuales deben estar sometidas al poder del Estado en el nombramiento de cargos y en la disciplina exterior.

Una noción protestantizada de la religión; indiferentismo en la base de su doctrina sobre la tolerancia religiosa - con intuiciones magníficas, hay que decirlo, sobre la dignidad del hombre y los derechos de la persona-, antiromanismo, galicanismo y regalismo en las relaciones IglesiaEstado marcan las características más destacables de la posición religiosa de Rocafuerte en 1829.

Ya en México Rocafuerte llega a la cumbre de su pensamiento religioso, cuando escribe su "Ensayo sobre la tolerancia religiosa", que le pondrá en el centro del debate político azteca. En la introducción se plantean las tesis básicas de la obra: en Europa la reforma religiosa precedió a la libertad política; en América, la reforma política precede a la libertad religiosa. Esta última será el medio más eficaz para que los pueblos americanos puedan ser no sólo independientes, sino verdaderamente libres ${ }^{4}$.

El Estado no satisface todas las necesidades humanas, sino que se limita a los intereses civiles, a lo justo y a lo injusto. Cuando éste abandona el campo de lo terreno encontraría a su misma naturaleza. La religión,

3 Mecum, Keneth: Vicente Rocafuerte ..., pág. 69.

4 Rocafuerte, Vicente: Ensayo sobre la Tolerancia Religiosa, en VR, II, pág. 380. 
por su parte, considera al hombre en sus relaciones con Dios y con su salvación. Fijados ya los principios de separación de religión y Estado, y negando el derecho de cualquier religión a erigirse en exclusiva, Rocafuerte analizará las políticas religiosas implementadas en diversas partes del mundo. A continuación, Rocafuerte pasa a describir algunas aplicaciones prácticas de la tolerancia. La más beneficiosa es que ésta facilita el asentamiento de colonias de ingleses, suizos y alemanes, personas que por su alto grado de civilización, por sus costumbres morigeradas y por su espíritu de trabajo son las más idóneas para hacer progresar a las sociedades hispanoamericanas.

Todas las doctrinas sostenidas en el "Ensayo" habían sido abordadas en sus escritos anteriores, pero ahora los presenta en un todo organizado y coherente. De sus páginas se desprende un concepto de tolerancia basada en el indiferentismo y contraria, por tanto, a la doctrina de la Iglesia. Quizá donde más se aleje Rocafuerte del dogma católico sea en lo referente a las relaciones con el Papa y a la función de la jerarquía dentro de la Iglesia. A pesar de que al principio de la obra Rocafuerte señala con toda claridad la distinción que debe haber entre poder espiritual y poder temporal, a la hora de referirse al Romano Pontífice le niega casi todo poder espiritual en las iglesias locales. El galicanismo a ultranza sostenido por Rocafuerte llevaría en la práctica a la creación de iglesias cismáticas y, por tanto, no católicas.

\section{Política religiosa de Rocafuerte en Ecuador (1833-1847)}

Una cosa es el sistema de ideas que Rocafuerte ha ido forjando a lo largo de la juventud y madurez, y otra muy distinta la posibilidad de plasmar esas ideas en la realidad, la cual muchas veces se presenta indócil y arisca cuando se ha accedido al poder político y se intenta modificarla. El estadista ha de columbrar el grado de posibilidad de aplicación de que gozan sus proyectos, si no quiere estrellarse con la dura realidad que no perdona error en los cálculos. Debe delinear una política real que a veces no coincide plenamente con el ideal que el gobernante ha concebido en su mente.

La política religiosa implementada por Rocafuerte no es contradictoria con su pensamiento. Más bien cabría afirmar que en su política se matizan afirmaciones tajantes de sus escritos, y se priorizan algunos principios, relegando otros. Era el tributo que se debía pagar frente a una realidad 
social muy distinta a la de Filadelfia o Londres. La mentalidad regalista y patronal de Rocafuerte será subrayada en sus actos de gobierno, mientras que la tolerancia religiosa ocupará un segundo plano, aunque importante.

Rápidos sucesos políticos y militares, que no corresponde reseñar aquí, llevan a Rocafuerte a constituirse en Jefe Supremo de gran parte del territorio ecuatoriano. En los meses que ejerció el cargo tomó algunas medidas de gobierno que tenían relación con la Iglesia. Una de ellas causó un revuelo de regulares proporciones. El 18 de febrero de 1835 Rocafuerte convocaba a la Convención que debía reunirse en Ambato el 1 de junio. En uno de los artículos del decreto de convocatoria se estipulaba que los eclesiásticos con jurisdicción, los miembros de los cabildos eclesiásticos y los párrocos no podían ser elegidos como diputados por las provincias en que ejercieran su jurisdicción ${ }^{5}$. En Cuenca la disposición rocafortina causó notable disgusto. El vicario capitular cuencano decidió condenar dos artículos publicados en el periódico "El Ecuatoriano del Guayas" que trataban sobre este tema, defendiendo la decisión del Jefe Supremo ${ }^{6}$. Rocafuerte decide actuar con mano dura frente a la decisión del Vicario. Remueve al dignatario de su cargo y lo expulsa del país. El enfrentamiento con los religiosos cuencanos levantó barreras para su fácil elección como Presidente. La Convención, presidida por Olmedo, decide revocar el decreto de expulsión del Vicario (o Provisor) Mariano Vintimilla ${ }^{7}$. Así se serenaron los ánimos, aunque se dejaba claramente asentada la doctrina del Patronato estatal.

En junio de 1835 se reunía en Ambato la Convención nacional, que daría al Ecuador una nueva Constitución y un nuevo Presidente. La Constitución de 1835 afirmaba que la Religión Católica, Apostólica y Romana era la del Estado. Al referirse al deber del gobierno de protegerla con exclusión de cualquier otra se suprimían unas palabras presentes en la constitución de 1830: "en ejercicio del Patronato".

Pero la simple eliminación de este texto no significó un cambio de actitud por parte de la autoridad civil. Al contrario, Rocafuerte será el campeón en Ecuador de la mentalidad patronal en la primera mitad del siglo XIX.

5 Cevallos, Pedro Fermín: Resumen de la Historia del Ecuador desde su origen hasta 1845 , Ambato, 1974, XII, pág. 149.

6 Destruge, Camilo: Historia de la Prensa de Guayaquil, Guayaquil, 1988, págs. 133-4.

7 Vasconez Hurtado, Gustavo: El General Juan José Flores. La República 1830-1845, Quito, 1984, pág. 130.

8 Constitución de la República del Ecuador, Ambato 1835, a. 13, en Noboa, A.: Recopilación de Leyes del Ecuador, Quito, 1900, I, pág. 135. 


\section{Presidente de la República del Ecuador (1835-1839)}

El 8 de agosto de 1835, Vicente Rocafuerte prestaba juramento como Presidente Constitucional de la República. En esa oportunidad dirige unas palabras a la Convención. Escuetísimas las referidas a política religiosa: "Se empeñará en que la Religión tenga el esplendor que corresponde a su celestial origen, haciendo brillar la divina caridad en hospitales, hospicios y Casa de Beneficencia".

Anteriormente ya se había dirigido a la Convención. En el mensaje que envía desde Quito se extiende con más amplitud en los temas tocantes a política religiosa. Allí critica la constitución de 1830: "Al lado de las declaraciones de la soberanía del pueblo, de la creación de un cuerpo legislativo, de la distribución de poderes, de la libertad de imprenta, y otras semejantes, que son puramente democráticas, están la intolerancia de otros cultos fuera del romano, el reconocimiento de fueros privilegiados, el pupilaje de los indígenas, y el statu quo de los establecimientos eclesiásticos y monacales, que han consagrado nuestras leyes coloniales"10. Así mismo, animaba a los convencionales a legislar sobre "la reforma del clero, la pureza de sus costumbres, la dignidad del culto, la educación de los sacerdotes, la abolición de ciertos abusos, la extinción de tantos días de fiesta, que entorpecen el desenvolvimiento de la riqueza" ". Se alentaba así, desde la Presidencia, un movimiento reformista que daba carta blanca a la intromisión del poder civil en campos ajenos a su incumbencia.

Uno de los centros de atención privilegiados de la política de Rocafuerte fue la educación pública. Consideraba con razón el guayaquileño que la independencia, la libertad y la prosperidad material de la Nación no se lograrían si no se extendían las luces de la educación sobre las grandes masas ciudadanas. El cuadro que presentaba la educación pública en Ecuador en 1835 era para desanimar al más entusiasta. Rocafuerte, sin embargo, salvó obstáculos y dio pasos significativos en el adelantamiento de este aspecto fundamental de su acción gubernamental.

La institución que había realizado un esfuerzo más sostenido en favor de la educación a lo largo de la historia del Reino de Quito era, sin duda, la Iglesia. Con ella tuvo que contar Rocafuerte para llevar a término sus

9 Discurso, Ambato, 8 de agosto de 1835, en VR, IV, págs. 49-50.

10 Mensaje de Vicente Rocafuerte a la Convención de Ambato, 1835, en VR, IV, pág. 16.

11 Ibídem. 
proyectos. Pero esta colaboración no estuvo exenta de dificultades. En el mensaje que Rocafuerte enviara a la legislatura de 1837 informaba que en el antiguo Beaterio se estaban realizando grandes progresos, debidos "al esmero, actividad y perfecta consagración de un benemérito profesor de los Estados Unidos, y de la dignísima señora que dirige el establecimiento"'12. El "Benemérito profesor de los Estados Unidos" era Isaac Guillermo Wheelwright, antiguo cónsul en Guayaquil y cuáquero de religión. Las desavenencias con el obispo de Quito no se hicieron esperar. La lectura de la Biblia sin las notas del expositor católico fue una de las causas del enfrentamiento. La disputa doctrinal entre Wheelwright y el clero fue subiendo de tono a medida que los litigantes echaban mano a la pluma. Wheelwright escribió un folleto titulado "Cuatro palabras a los sabios", que fue refutado por el Presbítero José Miguel Clavijo y el Padre Solano entre otros ${ }^{13}$. El asunto podría haber pasado a mayores si no hubiera intervenido don Vicente, quien "prohibió que las prensas de Quito publicaran nada más al respecto"14. En agosto de 1836 Rocafuerte ordena mediante decreto que en los conventos masculinos de Quito se abrieran escuelas primarias que pudieran albergar a doscientos niños. Las monjas de la Concepción debían abrir una escuela similar para niñas ${ }^{15}$. En ese mismo año Rocafuerte secularizaba el Colegio de San Fernando, a cargo hasta entonces de los dominicos ${ }^{16}$. En 1836 el Presidente había dictado un "Decreto orgánico de enseñanza pública" ${ }^{17}$, al que le sucede un "Decreto reglamentario de instrucción pública"18. En estos dos instrumentos legales se abordaban aspectos de los estatutos y organización del Colegio de San Luis, seminario de Quito. Era otra extralimitación en el ejercicio del poder público. Sana era la obsesión de Rocafuerte por la educación, pero en lo referente a los establecimientos religiosos, llevado de su mentalidad patronal, avasalló derechos ajenos.

¿Cómo reaccionó el clero frente a estas disposiciones? Cuando el agente sueco Carl August Gosselman visitó Quito en 1837 informaba a su rey del malestar que reinaba entre el clero a causa de estas medidas. "A los que debe temer (Rocafuerte) —escribe en su informe-, son a los curas y

12 Mensaje de Vicente Rocafuerte al Congreso, 15 de enero de 1837, en VR, IV, págs. 127-128.

13 Tobar Donoso, Julio: La Iglesia Ecuatoriana ..., pág. 349.

14 Tobar Donoso, Julio: "La Instrucción Pública de 1830 a 1930”, en Monografías Históricas, Quito, 1937, pág. 471.

15 Mecum, Kent: Vicente Rocafuerte ..., pág. 181.

16 Cevallos, Pedro Fermín: Resumen de la Historia del Ecuador, XII, pág. 191.

17 Tobar Donoso, Julio: La Iglesia Ecuatoriana ..., pág. 339.

18 Ibídem, pág. 341. 
a los militares. A los primeros no les puede gustar de ninguna manera un presidente que quiere convertir los conventos en escuelas, que cree que los herejes pueden ganar el cielo y que quiere que el pueblo lea la Biblia; por consiguiente consideran que tiene tres cuartas partes de hereje por lo menos" 19 .

En su mensaje de 1837 el cuadro que pinta el Primer Magistrado no es halagador: la razón del pueblo "está obscurecida por la superstición, entorpecida por una especie de esclavitud feudal, y paralizada por hábitos arraigados de inercia y abatimiento". El clero, por su parte, está educado en las máximas de la inquisición. Y entre las reformas que propone tocantes a la Iglesia se encuentra la reducción de los días de fiesta ${ }^{20}$.

Para mejorar en algo la situación del clero, Rocafuerte había ordenado en 1836 a los Provisores que los párrocos que no se hallaban en sus parroquias retornaran inmediatamente a ellas. Esta disposición cobró eficacia cuando en julio de 1838 el Ejecutivo decide que no se admitan a los distintos concursos para cargos eclesiásticos a ningún clérigo que hubiera faltado al deber de residencia en los anteriores curatos ${ }^{21}$.

1837 será el año en que Rocafuerte lleve a cabo su máxima obra en materia religiosa, ésta sí, beneficiosa para la Iglesia: consigue que el Papa Gregorio XVI erija la diócesis de Guayaquil, separándola de la de Cuenca. El 22 de marzo de 1837 Rocafuerte ponía el "ejecútese" a la ley por la que se separaban las diócesis de Cuenca y Guayaquil, argumentando la gran extensión de la diócesis cuencana, la dificultad en las comunicaciones, y las necesidades espirituales de los fieles, que se verían mejor atendidas con dicha separación. El artículo cuarto de la ley dispone que el poder ejecutivo "dirigirá a Su Santidad las preces convenientes para que acceda a la erección del nuevo obispado de Guayaquil" "22. Pasada una semana exacta, el 29 de marzo, Rocafuerte nombraba al Dr. Francisco Xavier de Garaicoa obispo de la nueva diócesis ${ }^{23}$.

Las gestiones del Presidente con Roma tuvieron relativo éxito. Mediante una Bula del 29 de enero de 1838, Gregorio XVI erigía la diócesis de Guayaquil, y en el consistorio del 10 de febrero de ese mismo año

19 Citado por Mecum, Kent: Vicente Rocafuerte ..., pág. 8.

20 Mensaje de Rocafuerte al Congreso, 15 de enero de 1837, en VR, IV, pág. 123.

21 Tobar Donoso, Julio: La Iglesia Ecuatoriana ..., pág. 336.

22 Noboa, A.: Recopilación ..., II, pág. 216.

23 Loor, Wilfrido: "Guayaquil Sede Episcopal", en Arias Altamirano, Luis (Coord.): Diccionario Biográfico del Clero Secular Guayaquilense, Guayaquil 1970, pág.15. 
preconizaba como primer obispo de la diócesis al Dr. Francisco Xavier de Garaicoa $^{24}$. Pero Rocafuerte también había propuesto al canónigo Antonio Torres para el obispado de Cuenca. Las informaciones que llegan a Roma sobre el candidato a la silla cuencana —en particular las que envía el nuncio para Nueva Granada y Ecuador, residente en Bogotá, Mons. Baluffino eran del todo halagüeñas. La Santa Sede no consideró idóneo al candidato tan alabado por don Vicente, y la sede de Cuenca permaneció vacante largos años ${ }^{25}$.

Por la misma ley que fija las rentas del obispo de Guayaquil -cinco mil pesos anuales — , se erige la diócesis de Quito como metropolitana, de tal manera que todos los juicios eclesiásticos suscitados en Cuenca y Guayaquil que se apelasen encontrarían su segunda instancia en la capital de la República. La eliminación de Lima como metrópoli de las diócesis ecuatorianas impedía la posibilidad de que algunos juicios eclesiásticos se ventilasen fuera del territorio nacional, con jueces extranjeros. Fue éste un móvil importante que impulsó a Rocafuerte a erigir la nueva diócesis guayaquileña, paso necesario para convertir a Quito en sede metropolitana ${ }^{26}$.

La creación de la nueva diócesis muestra, a las claras, el poder que la autoridad civil se había abrogado en materias eclesiásticas: divide diócesis, nombra obispos, adjudica rentas, etc. Era el ideal galicano de Rocafuerte. En ese mismo año se dictan leyes como las de funerales, o de jubilación de los miembros del cabildo, que si no fuera porque tenían la firma de Rocafuerte podrían haber sido redactadas por José II de Austria, motejado como el "Rey Sacristán" e iniciador del josefismo, versión centro-europea del galicanismo francés o del patronato español y americano.

Pero el galicanismo de Rocafuerte no fue completo. Este es uno de los puntos donde su pensamiento y su política religiosa se separan. En el mensaje de Rocafuerte a la legislatura de 1839 se lee: "Su Santidad sigue dándonos pruebas de la paternal solicitud con que mira los intereses de la Iglesia Ecuatoriana: aprobó la erección de la nueva Diócesis de Guayaquil que el Congreso decretó en trece de abril de 1837 y confirmó la elección del nuevo Obispo, que el Ejecutivo hizo según los trámites constitucionales; y por el tenor de la Ley de Patronato, igualmente esperamos las Bulas

24 Arias Altamirano, Luis: Diccionario ..., págs. 19-23.

25 El caso Torres se encuentra documentado en los Archivos Vaticanos, AAEESS, fasc. 412, 919-97 y fasc. 413, 416 (gentileza del Dr. Santiago Castillo Illingworth).

26 Noboa, A.: Recopilación ..., II, págs. 325-6. 
del Obispo electo de Cuenca. Su Santidad ha expedido la bula para la supresión de los días de fiesta, que se sujetará a nuestra aprobación, por razones que os expondrá el Ministro de Relaciones Exteriores. Igualmente recibirá vuestra sanción el nombramiento de visitadores para los conventos de la República" ${ }^{27}$.

Rocafuerte había nombrado un encargado de negocios en Francia, España y la Santa Sede, don José Modesto Larrea. Se retractaba así de lo expresado en Londres al Ministro mexicano Bocanegra: "Si las legaciones de Francia, Inglaterra y Holanda son inútiles, mucho más lo es la de Roma" ${ }^{28}$. Monseñor Lambruschini, secretario de estado vaticano, comunicará a Larrea que el Romano Pontífice se ha dignado "riconoscere nella di Lei persona la qualità d'Incaricato d'Affari della Repubblica dell'Equatore presso la Santa Sede, anuando in tal modo ai desideri di quel suo Governo"29. Se concretaba así el reconocimiento, por parte de la Santa Sede, del Estado del Ecuador. Por su parte, Roma, nombrará un Internuncio apostólico para Nueva Granada y Ecuador, con residencia en Bogotá. El Presidente mantendrá relaciones amables con el representante de $\mathrm{Su}$ Santidad, Monseñor Baluffi, a quien solicita el nombramiento de visitadores para los conventos de Quito.

En 1839 Rocafuerte terminaba su mandato presidencial. Se había convertido en el primer civil de toda Hispanoamérica que concluía felizmente su período constitucional. El Mensaje de 1839 dedica largos párrafos a las reformas para mejorar el clero. Entre las reformas propuestas se encuentra la reducción del Coro de la Iglesia Catedral de Quito; que se unifique para todo el país el sistema de diezmos que rige en Guayaquil — los diezmos los cobraba directamente la Tesorería Nacional, suprimiendo así a los colectores y contadores, con el consecuente ahorro de setenta mil pesos-; la reducción de la renta del obispo de Quito; la abolición del fuero eclesiástico; la determinación por parte de las cámaras del número de sacerdotes; y la progresiva abolición de las órdenes religiosas ${ }^{30}$. Finalmente, como de costumbre, terminará por recomendar vivamente la adopción de la tolerancia religiosa.

27 Mensaje de Vicente Rocafuerte al Congreso, 15 de enero de 1839, en VR, IV, pág. 149.

28 Rocafuerte a José María Bocanegra, Londres, 6 de mayo de 1829, en Rodríguez, Jaime, Estudios ..., n. ${ }^{\circ} .109$, pág. 158.

29 Citado por Bermeo, Antonio: "Ideas religiosas de Rocafuerte", en Rocafuerte. Estudios sobre su compleja personalidad, Quito 1947, pág. 40.

30 Mensaje de Vicente Rocafuerte al Congreso, 15 de enero de 1839, en VR, IV, pág. 157. 
Rocafuerte había concluido su período presidencial. En los cuatro años de su mandato había llevado a cabo una política religiosa definida, puesto que con la ley de Patronato en la mano defendió y asentó la intervención de la autoridad civil en el campo eclesiástico. Clero diocesano, clero regular, educación, liturgia, bienes eclesiásticos, todo fue objeto de su tutela y de sus iniciativas legales. Dejaba un poder ejecutivo fortalecido, pero también dejaba a una Iglesia ecuatoriana cada vez más desconfiada de la autoridad civil.

\section{Gobernador del Guayas (1839-1843)}

Después de su período presidencial, Rocafuerte no abandonará la arena política: gobernador del Guayas, diputado, Presidente del Senado, diplomático, don Vicente se mantendrá activo en la vida pública hasta el día de su muerte.

En los primeros meses de 1840, Rocafuerte tuvo que capear un buen temporal causado por sus convicciones religiosas. El Gobernador del Guayas había enviado al Gobierno de Quito una nota donde exponía "el grave riesgo que correría nuestra libertad si admitiéramos en la República la autoridad de Roma en materia de contribuciones y de negocios puramente temporales". En nuestras investigaciones en el Archivo Histórico Nacional hemos descubierto la causa que motivó el envío de dicha nota: el obispo de Guayaquil, Garaicoa, se había negado a entregar el $10 \%$ de sus rentas, como se exigía según las leyes, argumentando que nada al respecto se estipulaba en la bula de erección de la diócesis, bula que, en virtud del exequatur otorgado por el gobierno, se había convertido en ley de la República. La nota que envía sobre este asunto Rocafuerte a Quito, el 18 de diciembre de 1839, a pesar de su carácter confidencial, comenzó a circular por la capital. La reacción de Rocafuerte es lo bastante importante como para no perderse palabra: "En cuanto a la circulación de mi nota entre los fanáticos de Quito - escribía un 12 de febrero—, nada se me da; al remitirla al Gobierno, preví todo lo que ha sucedido, porque conozco que entre nosotros no hay secreto alguno, que no hay en todas las oficinas un hombre que desempeñe fielmente su destino; porque Valdivieso y otros están acechando mis movimientos para desacreditarme, pero tiempo vendrá en que esos miserables y rastreros manejos salgan a la luz y me proporcionen la ocasión de probar que el país está mucho más atrasado en princi- 
pios de honor, de política y de moral, de lo que yo he expuesto al público en mis comunicaciones oficiales. El oficial mayor de la secretaría de Estado, a que pertenece este asunto, que ha franqueado una copia de esta nota ha cometido una falta, que merece un severo castigo; las ideas contenidas en mi nota son las más exactas y las que siguen todos los hombres algo instruídos, que conocen la marcha de los negocios públicos, y están penetrados de la importancia de no consentir nunca que haya dos autoridades en la República, una en Roma y otra en Quito, tratándose sobre todo de asuntos muy temporales, como son los que hacen relación al pago de contribuciones. Le aseguro que lejos de enfadarme porque me hagan pasar por hereje, me lleno de ufana complacencia y les agradezco la circulación de esta noticia, porque hereje en el vocabulario del siglo 19 significa hombre ilustrado, que no sigue el vulgar sendero de añejas preocupaciones y cuya razón despejada es superior a los errores, que un clero astuto sabe cubrir del manto del egoísmo religioso, para engañar a los pueblos y sacar de su credulidad el dinero que necesitan. Mientras más repitan que soy un grandísimo herejote, tanto más honor me hacen, pues es lo mismo que decir que en medio de tanta ignorancia y tanta superstición, no falta un verdadero ecuatoriano que sostenga con desinterés y firmeza los principios del siglo y que impertérrito campeón de la libertad racional, considerada bajo todos sus aspectos, ha desdeñado cubrirse con la máscara de la hipocresía, que siempre está de moda entre los fanáticos y esclavos de Roma. La aura popular no conmueve ya mi sensibilidad, ha perdido ese suave aroma, que en los primeros años de vida, tanto me halagaba" ${ }^{31}$.

Volvía otra vez don Vicente a sus antiguos ataques a Roma, que en gran medida se habían suavizado en su período presidencial. Sin embargo, las relaciones entre este "grandísimo herejote" y el flamante obispo de la diócesis por él propuganda, Mons. Garaicoa, no fueron tan malas como puede suponerse.

Un motivo de discusión fue la negativa de Rocafuerte de prohibir la circulación de unas biblias protestantes. El 18 de marzo de 1840 le comentaba por carta a Flores que "el Señor Obispo, según dicen está muy bravo conmigo: él se empeñó en que yo prohibiese la circulación de los Santos Evangelios sin notas ni comentos y como la ley de la materia del 27 de marzo de 1835 no los prohibe, no he podido acceder a su solicitud. En una

31 Rocafuerte a Flores, Guayaquil, 12 de febrero de 1840, en Rodríguez, Jaime: Estudios..., n. ${ }^{\circ} 249$, págs. $313-314$. 
segunda nota bastante templada volvió a insistir y yo le contesté insistiendo en la negativa; mi contestación es sumamente suave y moderada en el modo, pero muy enérgica en los argumentos que prueban la mentecatez de semejante prohibición eclesiástica"32.

A pesar de las lecciones teológicas que el Gobernador se atreve dar al Obispo, las relaciones entre los dos fluyeron por cauces tranquilos. El 15 de abril de 1840 Rocafuerte visita a Garaicoa y le encuentra "de excelente humor, alegre, contento y muy satisfecho de U. (Flores), del Consejo de Gobierno, y de todos los que componen la actual administración"33. El gobernador aprovecha la ocasión para explicarle que todas las acusaciones que caen sobre el gobierno son calumnias de sus enemigos. Y en agosto de ese mismo año, cuando se aproximaban las elecciones para renovar las cámaras legislativas, vuelve a visitar al Obispo: "le hice una reseña del estado político en que estamos y de la necesidad de su cooperación, que yo imploraba, con el objeto de afianzar la paz interior. Le encontré muy amable y me prometió trabajar de acuerdo con el Gobierno para que la elección sea acertada y a satisfacción de todos los hombres sensatos y así puedo asegurar a U. que ganaremos las elecciones". Este pedido de colaboración política al obispo contradice la teoría defendida por Rocafuerte a lo largo de toda su vida sobre la conveniencia de que los eclesiásticos no intervengan en política. En la convención de 1843 será tajante al tratar sobre este asunto en los debates.

Durante su período de gobernador, Rocafuerte contrae cristiano matrimonio con doña Baltasara Calderón y Garaicoa, sobrina a la sazón del obispo guayaquileño. Cuando en 1842 estalle en la ciudad una terrible epidemia de fiebre amarilla, el pueblo verá que tanto el Gobernador como el Obispo hacen denodados esfuerzos por paliar en algo la caótica situación material y espiritual que se desencadenó. Murieron unas tres mil personas, cifra impresionante si tomamos en cuenta que la ciudad no alcanzaba los veinte mil habitantes. Las circunstancias lograron unir al tío y al sobrino político $^{34}$.

Se acercaban los últimos meses de su periodo gubernativo. Tuvo tiempo aún de crear un cementerio no confesional. Decidió, además, que en ausencia de un ministro protestante, un sacerdote católico debía bendecir la

32 Rocafuerte a Flores, Guayaquil, 18 de marzo de 1840, en ibídem, n. ${ }^{\circ}$ 253, pág. 320.

33 Rocafuerte a Flores, Guayaquil, 15 de abril de 1840, en ibídem, n. ${ }^{\circ}$ 255, pág. 325.

34 Huerta, Pedro: Rocafuerte y la epidemia de fiebre amarilla, Guayaquil 1987, passim. 
sepultura. A este propósito, Fray Vicente Solano comentaba: "El proyecto de Rocafuerte acerca del panteón protestante, bendito por un sacerdote católico, es una de las cosas propias de su cabeza. El sacerdote que bendijera, quedaría excolmulgado; porque nos está prohibido comunicar in sacris, como dicen, con los herejes. Yo creo que el obispo de Guayaquil no lo consentirá; y si lo consiente, me río de él. Es razonable que haya un lugar destinado para sepultar los cadáveres de los herejes; y si quieren bendición, que lo hagan sus ministros" ${ }^{\prime 35}$.

\section{Últimos años (1843-1847)}

Conforme se iba alejando de las más altas esferas del poder, Rocafuerte volvía a planteamientos más extremos, más concordes con sus épocas londinense y mexicana. Su pensamiento, manifestado en sus cartas, a ratos se radicaliza. Pero su acción gubernativa, su política, siguió discurriendo por cauces más o menos tranquilos, moderados, aunque sin entrar en flagrante contradicción con su pensamiento. En la Convención de 1843 propone la libertad de cultos. Se apoya en los argumentos ya tradicionales en él: la adopción de la tolerancia religiosa en los países católicos Argentina, Venezuela, Brasil— no produjo ningún daño a la fe del pueblo; "la exclusión de todo culto exterior embaraza cualquier proyecto de colonización europea, que sólo puede realizarse, apoyándose en la base de la libertad de cultos, sin la cual no puede haber libertad política"; "las naciones que no admiten en su seno la libertad de cultos, son las más atrasadas de luces y civilización"36.

El 2 de marzo, don Vicente aborda otro tópico de su pensamiento religioso: el clero no debe intervenir en política. La religión trata de las cosas del cielo, y la política las de la tierra. La división de estos dos ámbitos está trazada por "la filosofía sin impiedad y por la religión sin fanatismo" ${ }^{37}$. La Constitución de 1843 consagraría estas ideas. En su artículo 36 afirma que "están excluidos de ser Senadores y Representantes (...) los Ministros del Culto".

35 Solano, Fr. Vicente: Epistolario, Cuenca, 1953, págs. 104-105.

36 Intervención de Vicente Rocafuerte en la Convención de Quito, febrero de 1843, en VR, IV, pág. 87.

37 Intervención de Vicente Rocafuerte en la Convención de Quito, 2 de marzo de 1843, en VR, IV, pág. 89. 
En la Convención de 1845 se opone, sin lograrlo, a la exclusión de la mención del Patronato en el texto de la Constitución Nacional ${ }^{38}$. Pocos días más tarde, el 28 de noviembre, se trata en la Convención sobre el artículo referente a la religión del Estado. Don Vicente, ducho en la materia, remozará viejos argumentos, blandidos en sus épocas londinense y mexicana ${ }^{39}$. A pesar de su oposición, el artículo 13 de la Constitución se referirá a la religión del Estado.

Una vez que fue discutida y aprobada la constitución, se pasó a elegir a los primeros mandatarios de la nación. El 4 de diciembre Rocafuerte es elegido Presidente del Senado, habiendo obtenido 28 votos sobre un total de $38^{40}$. Durante su gestión se opone a la unión de las diócesis de Guayaquil y Cuenca, propuesta por el clero austral ${ }^{41}$. A pesar de su delicado estado de salud, que terminará por alejarlo de la presidencia del Senado, intervino largamente y de forma concienzuda en gran número de sesiones. Sobre política religiosa se explayó en dos oportunidades más. Una de ellas versó sobre la inmunidad del clero y sus privilegios ${ }^{42}$; la otra sobre la posibilidad de readmisión de los jesuitas en Ecuador, posibilidad a la que se muestra contrario.

Sobre este último asunto, Rocafuerte se apoyaba en la experiencia europea y americana para rechazar la posible readmisión de la Compañía de Jesús, a fin de que atendieran algunas misiones. El 14 de octubre de 1846, según reza el acta del Senado, así respondía a un informe presentado sobre este tema tan delicado: "Con esta ocasión tomó la palabra el Honorable Presidente y dijo: esta es una cuestión sumamente delicada: consultemos los hechos y la historia para no dejarnos alucinar. La Compañía de Jesús tuvo su origen en el tiempo en que Lutero y Calvino comenzaron a propagar sus ideas promoviéndose entonces unas luchas reñidas entre los protestantes que predicaban la emancipación; y los católicos que aspiraban a conservar la pureza de la doctrina evangélica. San Ignacio y el Padre Laines quisieron poner contra las novedades una institución fundada en la inteligencia y la virtud: insertada sobre tan firmes bases

38 Archivo Honorable Congreso Nacional (AHCN), 2..$^{\circ}$ libro de actas ordinarias del año de 1845, Convención Nacional de 1845, sesión del 20 de noviembre de 1845, págs. 21-22.

39 Ibídem, sesión del 28 de noviembre de 1845, pág. 88.

40 Ibídem, sesión del 4 de diciembre de 1845, pág. 129.

41 AHCN, Actas de la Cámara del Senado del año de 1846, sesión del 9 de enero de 1846, pág. 52 .

42 Ibídem, sesión del 3 de octubre de 1846, pág. 40. 
no pudo menos que prestar grandes servicios a las letras y a las ciencias y a las costumbres; pero la bondad de este instituto solamente duró cientocincuenta años; porque con su agradecimiento la ambición se apoderó de sus miembros, y setenta u ochenta mil jesuitas a las órdenes de un jefe despótico, llegaron a ser nocivos a la sociedad y se labraron su persecución. Es verdad que Federico el Grande acogió a los expatriados, pero a los veinte años tuvo que arrojarlos de Silesia por las disensiones que sembraron entre católicos y protestantes. Catalina II los admitió también; pero Alejandro los ha expelido en número considerable y no existe ninguno en Rusia. Buenos Aires ha tocado los mismos extremos de admisión y expulsión; y la Nueva Granada que los ha llamado a su seno tendrá también que volver atrás, después de haber sufrido la severa censura de todos los hombres que conocen el curso de los negocios humanos. Los jesuitas ni hacen falta para la educación que ha progresado sin ellos, ni son calculados como el informe lo cree para servirnos en las misiones; ellos encuentran su teatro en las ciudades donde pueden influir en las conciencias de los que mandan, y en los intereses del gran mundo: los jesuitas no son los héroes del desierto; no entran en los bosques a recibir el martirio en cambio de la predicación. La comisión eclesiástica del Senado de 1846 recuerde esta historia y espíritu de la corporación jesuítica, para emitir el informe que debe presentar, y recuerde así mismo que más cerca de nosotros tenemos a quien puede servir para el fin que se desea, el Padre Plaza; este sacerdote benemérito del siglo ha hecho venir a Ocopa misioneros españoles, de donde nos lo pueden mandar, si nosotros tenemos la conducta de pedírselos más bien que llamar a los jesuitas para despedirlos mañana" ${ }^{43}$.

¿Desconocía Rocafuerte la larga lista de mártires jesuitas, muertos por propagar la fe en Extremo Oriente y en América? Los prejuicios antijesuíticos afloran de los labios de Rocafuerte, que no se pudo excluir de la corriente de opinión dominante de su tiempo. Pasarían algunos años hasta su readmisión en el Ecuador.

Rocafuerte emprenderá nuevamente los caminos americanos, esta vez para desempeñar funciones diplomáticas en Lima. Ya no regresaría al Ecuador: el 16 de mayo de 1847 entregaba su alma al Creador. De los últimos momentos de don Vicente caben destacarse dos hechos importantes para el estudio de su pensamiento religioso: su testamento y la recepción de los últimos sacramentos.

43 Ibídem, sesión del 14 de octubre de 1846, pág. 63. 
El 21 de abril de 1847, faltando escasos días para su muerte, Rocafuerte dictaba su testamento. Los primeros párrafos son una declaración de fe absolutamente ortodoxa y de gran contenido piadoso ${ }^{44}$. El, según algunos, "grandísimo herejote", hacía humilde confesión de su fe católica. Sin embargo, en el momento de recibir los últimos sacramentos, lo hace de manos de un sacerdote cismático. Apunta Mecum que "en Lima había muchos clérigos; él quiso que le ministrara los santos óleos Francisco de Paula González Vigil, sacerdote excomulgado, que había atacado a la Iglesia de Roma acusándola de ser un monopolio religioso y que deseaba establecer una Iglesia Católica Peruana" ${ }^{45}$. Cabría aplicar la castiza frase: "Genio y figura hasta la sepultura". Rocafuerte, desde el punto de vista religioso, murió como había vivido: en el seno de la Iglesia Católica, pero aportando un toque personal. La elección del sacerdote cismático confirma la tesis de Jijón y Caamaño: el catolicismo de Rocafuerte fue sui generis hasta el último momento de su vida.

\section{Conclusión}

Después de haber pasado revista a las acciones y escritos político-religiosos de Rocafuerte, elaboraremos una conclusión de todo lo dicho hasta aquí.

En primer lugar, cabe señalar que la evolución del pensamiento religioso rocafortino es lineal, sin cortes abruptos ni desviaciones dispersivas. Tal evolución podría calificarse de un crescendo gradual, según el cual en cada período se decantan los elementos anteriores y se añaden nuevos. El crescendo cesaría en 1832, cuando escribe su "Ensayo sobre la tolerancia religiosa". Esta obra marca el cénit, la madurez de su pensamiento religioso.

Las relaciones y el ambiente en el que se desenvuelve durante la juventud imbuyen a don Vicente del espíritu del siglo, racionalista y romántico a la vez en sus corrientes de pensamiento, y anticlerical y regalista en lo religioso. El compromiso político adoptado por algunos eclesiásticos con las estructuras del Antiguo Régimen, y la política vacilante de León XII, temeroso de enfrentarse con los intereses de la Santa Alianza, impulsan a Rocafuerte a combatir las actividades políticas del clero. Tal era el cariz de sus primeros escritos.

44 Testamento del S. D. Vicente Rocafuerte, en VR I, pág. 107.

45 Mecum, Kent: Vicente Rocafuerte..., págs. 221-222. 
Desde un primer momento consideró a la religión —en particular al Cristianismo - como un elemento esencial de la condición del hombre, pero pensaba que era necesaria una depuración de la religión y, de este modo, se debían quitar las adherencias humanas que con el paso de los siglos se habían incrustado en su seno. La carencia de una formación teológica seria hizo que Rocafuerte no acertara en el deslinde de lo divino y lo humano. Lo que comienza como una simple oposición política a las actividades del clero en campos ajenos a lo espiritual - y eso sí era un elemento humano y dañino- se convierte imperceptiblemente en un alejamiento de la doctrina ortodoxa. En Londres ya encontramos asertos temerarios en materias puramente teológicas.

A su falta de formación dogmática se añade el influjo del protestantismo, muy en especial del cuaquerismo. Estos dos elementos hacen eclosión en la definición rocafortina de religión - un sentimiento interior- y en la función que le adjudica en la sociedad: el mantenimiento del orden y la beneficencia pública son los dos grandes servicios que prestaría el Cristianismo a la sociedad política.

Para que el Cristianismo cumpla con estos fines no es necesaria ninguna dependencia de la autoridad del Romano Pontífice, vista por Rocafuerte con marcada desconfianza y recelo. Así, las relaciones IglesiaEstado se concretan en el pensamiento del guayaquileño en un galicanismo acusado - creación de iglesias nacionales- y un regalismo sofocante -invasión por parte del Estado de campos propiamente eclesiásticos-. Y como esta obra de moralización la puede llevar a cabo cualquier secta cristiana - aunque en sus obras Rocafuerte se inclinará por preferir al protestantismo - campeará por toda su producción un indiferentismo contrario a la fe católica.

Cuando accede al poder político, estos principios pasan por el tamiz de las circunstancias propias del Ecuador de 1835. No es que Rocafuerte se haya moderado en sus planteamientos, sino que simplemente no era posible ponerlos en práctica de una manera tan radical. Cuando deja la presidencia, el tono de sus escritos recupera la radicalidad de los años anteriores.

Vicente Rocafuerte fue católico: constan, entre otros muchos elementos de juicio, su bautismo, su matrimonio eclesiástico, la recepción de la extrema unción y del Santo Viático, etc. Pero fue católico a su modo. El análisis de su biblioteca podría darnos la clave ${ }^{46}$ : habiendo leído y estudia-

46 Mecum, Kent: Vicente Rocafuerte..., págs. 239-265. Mecum trae el listado completo de la biblioteca rocafortina. 
do a todos los prohombres de la ilustración y del incipiente liberalismo, estaba empapado de las ideas de su tiempo. Al carecer de un asidero doctrinal sólido, forjó en su mente un cuerpo doctrinal propio, que él consideró como ese cristianismo depurado de adherencias humanas, donde el protestantismo, el racionalismo y una buena dosis de prejuicios juegan un papel importante. A su vez, la confusión de ideas de muchos clérigos sobre las relaciones Iglesia-Estado, libertad religiosa, etc., facilitó su propia confusión doctrinal.

Ateniéndonos a su política y pensamiento religioso, don Vicente Rocafuerte fue, sin lugar a dudas, un liberal. Su período presidencial es un antecedente importante de las futuras luchas enconadas entre el Estado Ecuatoriano y la Iglesia.

El lugar que Rocafuerte ocupa en la historia del Ecuador es de primer orden. Sus méritos son muchos e incuestionables. Pero en su concepción religiosa fue un hijo de su tiempo: ni más ni menos.

Recibido el 19 de diciembre de 2005 Aceptado el 22 de mayo de 2006 